\title{
The Effect of an Animation Video and Music on Anxiety and Pain Scores Before TRUS-guided Biopsy
}

\author{
๑ Hasan Turgut ${ }^{1,2}$, ๑ Güner Kemal Özgür² \\ ${ }^{1}$ Faculty of Health Science, Avrasya University, Trabzon, Turkey \\ 2Medicalpark Karadeniz Hospital, Clinic of Urology, Trabzon, Turkey
}

\begin{abstract}
Objective: The aim of this investigation is to investigate the effect of a pre-procedure animated video and music on blood pressure, pain score, anxiety score and pulse rate in patients undergoing transrectal ultrasound (TRUS)-guided biopsy.

Materials and Methods: One hundred and two male patients who underwent a TRUS-guided prostate biopsy were randomised into two groups. A control group: no music or with a video included $(n=51)$ and an experimental group: pre-education with an animation video and music included $(n=51)$ during the procedure. Before and after the TRUS biopsy, the state-anxiety inventory score (STAI), pain visual analogue scale (VAS), heart rate and blood pressure were obtained from each patient and compared. Blood pressure and pulse were recorded by the urologist. Student's t-test and a paired t-test were used for variables with a normal distribution and Mann-Whitney $\mathrm{U}$ test and Wilcoxon-rank tests were used for variables that did not show a normal distribution $(p<0.05)$.

Results: There were no differences prostate-specific antigen, age and prostate volume between the two groups. VAS, STAI scores and pulses differed between the two groups before and after the procedure. There was no difference in systolic and diastolic blood pressure values before the procedure. However, a significant difference was found between the two groups regarding these values after the procedure. There was a statistically significant difference in the VAS, STAI, blood pressures and pulse rates after the procedure compared with the pre-procedure values $(p<0.05)$.

Conclusion: Watching the animation video and listening to music positively affected patients' anxiety, pain score, blood pressure and pulse values. This method is a low-cost, readily available application, which might be preferred by particular patient groups.

Keywords: Anxiety, pain score, transrectal ultrasound-guided prostate biopsy
\end{abstract}

\section{Introduction}

Transrectal ultrasound (TRUS)-guided biopsy is the gold standard for prostate cancer diagnosis. However, the procedure is both painful and uncomfortable for many patients. Therefore, different methods should be applied to relieve the patient's anxiety and pain $(1,2)$. Two factors cause patient discomfort during the biopsy procedure. First is the movement of the ultrasound probe in the rectum, and the other factor is the pain caused by inserting the biopsy needle into the prostate tissue (3). In addition, anal tension and patient anxiety affect the tolerance to pain (4). Various procedures have been applied to reduce pain and anxiety before and during such procedures performed under local anaesthesia $(5,6)$. Music therapy has been used for many years in medicine and has been shown to have a relaxing effect on pain and anxiety in many cases $(5,6)$. Although music therapy is a useful and cost-effective method with positive effects on pain and anxiety, there is not sufficient information about the effect of watching an animation video in addition to music.

Therefore; the aim of this study is to investigate the effect of music video therapy on pain and anxiety in patients who underwent TRUS-guided biopsy, in addition to watching an animation video about the biopsy pre-procedure.

\section{Materials and Methods}

A total of 102 patients admitted for TRUS-guided prostate biopsy from February 2018 to February 2020 after obtaining the approval of the Ethics Committee (approval no: 2001/18/108). Patients had either a prostate-specific antigen (PSA) elevation (PSA $>4.0 \mathrm{ng} / \mathrm{mL}$ ) or abnormal findings on a digital rectal examination. They were randomly allocated to the control (group 1, n=51) and experimental groups (group 2, n=51). Exclusion criteria were any anorectal pathology, hearing loss, any psychiatric disease, current analgesic medication, allergy to 
lidocaine or a previous TRUS-guided biopsy. Demographic data, serum PSA and prostate volume were recorded. Physiological indicators (eg, heart rate and blood pressure) were measured, the state-anxiety inventory (STAI) was applied, and pain visual analogue scale (VAS) scores were collected by a blinded urologist pre- and post-biopsy.

All TRUS-guided biopsies were performed by the same surgeon (H.T.). No patients were administered a rectal enema on the day before the biopsy. However, all patients underwent rectal povidone-iodine preparation for biopsy and received antibiotic prophylaxis of Trimethoprim-Sulfametaxol one day before the biopsy (7). The procedure was explained in detail, and all patients signed an informed consent form.

Patients in the experimental group watched and explained the details about a five-minute animation video (Prostate biopsy YouTube animation video, open to everyone, free access. https://www.youtube.com/watch?v=NGh025wYK20) before the procedure, then completed the STAI form. After the biopsy was planned, patients were asked to select the type of music that they would provide them comfort. The patient's musical selection was played continuously during the procedure. Patients were not restricted in the choice of music. Headphones were not used to enable continuous contact with the doctor. A controlled environment was created to minimise the effects of additional variables. All patients were positioned in the lateral decubitus position with knee flexed and hip extended. Four to five minutes before probe introduction, $2 \%$ lidocaine and chlorhexidine gel was introduced into the patient's rectum, and $5 \mathrm{cc}$ lidocaine injections were performed in the right and left the periprostatic area. Then, 12 core biopsies of the six right lobes and six left lobes were taken from all patients. The biopsy procedure took an average of 15-20 minutes. VAS values were recorded when injections were given for the periprostatic blockade and immediately after the procedure. Patients selfreported their pain according to the VAS.

VAS scores range from 0 to 10 , where $0=$ no pain and 10 =intolerable pain (8). The STAI score measures the level of anxiety in patients under certain stress. The scale has 20 items scored using a 4-point Likert scale of patient responses: 1-"not anxious at all", 2-"moderately anxious", 3-"very anxious" and 4-"extremely anxious" The total score can range from 20 to 80 , with a lower score indicating a lower anxiety level. The scores were evaluated as 20-39 mild anxiety, 40-59 intermediate anxiety and $60-80$ severe anxiety.

\section{Statistical Analysis}

Continuous variables were reported as the mean \pm standard deviation (SD) and analysed for normal distribution using a histogram and the Kolmogorov-Smirnov test. Variables with normal distribution were analysed using the Student's t-test and paired t-test. Continuous variables not showing a normal distribution were analysed with the Mann-Whitney $U$ test and the Wilcoxon-rank test for the same groups $(p<0.05)$.

\section{Results}

The patients in the control group had a mean age of $61.2 \pm 6.6$ years, PSA value of $7.7 \pm 1.9$ and prostate volume of $54.2 \pm 12.4$.
The experimental group patients had a mean age of $62.1 \pm 5.2$ years, PSA value of $7.48 \pm 1.8$ and a prostate volume of $56 \pm 10.6$. No significant difference was found between the groups regarding age, PSA level and prostate volume (Table 1). The post-biopsy VAS scores were significantly different in both groups compared with the pre-biopsy values $(p<0.05)$. A significant difference was found in each group in systolic and diastolic blood pressures post-biopsy compared with pre-biopsy values $(p<0.05)$. However, there was no difference between the two groups before the procedure $(p>0.05)$. A significant difference was found between the pre- and post-biopsy STAI anxiety scores and pulse values both within the groups and between the two groups $(p<0.05)$ (Table 2).

\section{Discussion}

Music therapy has been used for many years during surgical procedures under local anaesthesia and is thought to have a relaxing effect on patients. The present study started with the idea that watching a detailed animation video and music about the procedure may have a positive effect on anxiety scores, pain scores and cardiac parameters.

The TRUS-guided prostate biopsy for prostate cancer diagnosis is a routine outpatient procedure. However, despite the application of lidocaine gel combined with the periprostatic blockade, a certain level of fear, anxiety and agitation remains (9).

The avoidance of pain in men undergoing a TRUS-guided prostate biopsy is highly desirable, so various methods have been applied in attempts to control this situation (10).

Many studies have shown that music therapy provides the patient relief after surgery or an invasive procedure $(5,11)$. In clinical studies, music has positive effects on physiological and psychological parameters and has also been reported to have anxiolytic properties and positive effects in stressful interventions (12). In the current study, music therapy and animation video were used in outpatient TRUS-guided prostate biopsy patients, and positive results were obtained on pain scores and anxiety.

The soothing effect of music reduces fear and anxiety in patients and has been shown to make it easier for the patient to tolerate the procedure in re-biopsy cases (13). However, studies are showing that music does not affect anxiety scores, heart rate or blood pressure. In a study by Ebneshahidi and Mohseni (14), music chosen by patients undergoing caesarean section was seen to decrease pain and analgesic requirements in the postoperative period. However, no change in anxiety scores, heart rate and blood pressure were observed (14). Another study showed that the music did not change the STAI and pain scores (15). Although it has been investigated whether pre-procedure training would have an effect with music, no consensus has

\begin{tabular}{|l|l|l|l|}
\hline \multicolumn{3}{|l|}{ Table 1. General information } \\
\hline & $\begin{array}{l}\text { Control (MD } \\
\pm \text { SD) }\end{array}$ & $\begin{array}{l}\text { Experimental } \\
(\text { MD } \pm \text { SD) }\end{array}$ & p-value \\
\hline Age (years) & $61.2 \pm 6.6$ & $62.1 \pm 5.2$ & 0.45 \\
\hline PSA (ng/dL) & $7.7 \pm 1.9$ & $7.48 \pm 1.8$ & 0.56 \\
\hline Prostate volume $\left(\mathrm{cm}^{3}\right)$ & $54.2 \pm 12.4$ & $56 \pm 10.6$ & 0.19 \\
\hline SD: Standard deviation, PSA: Prostate-specific antigen, MD: Mean difference \\
\hline
\end{tabular}


been established $(6,16)$. During the procedure, the patient faces the opposite side and cannot see the procedure. Therefore, an animation video explaining the process in detail can be shown to the patient before the process. In this study, the experimental group watched an animation video with music before the process. As a result, a significant difference was observed in systolic and diastolic blood pressure values, pulse and STAI anxiety scores in the patient group informed by animation with music. Although the pre-procedure values were not the same between the two groups, the decrease in STAI scores in the experimental group was significant compared with the post-biopsy value of the control group. This finding is especially important for patients receiving antipsychotic treatment or psychiatric problems. We believe that watching music and animation videos will comfort this group of patients.

TRUS biopsy may cause a rise in blood pressure. This increase may cause hypertensive attacks in patients with uncontrolled hypertension, angina and arrhythmias in patients with coronary artery disease and dyspnoea in patients with heart failure.

In the study, blood pressure values were recorded in both groups before the procedure. Changes in systolic and diastolic blood pressures after the procedure suggest that music and video may be an effective tool for blood pressure (Table 3).
Some studies reported that music might distract patients from anxiety and worries and reduce pain and distress $(17,18)$. However, another study showed that listening to music during or after the biopsy had no significant pain reduction in patients (19). In this study, the VAS score was mild to moderate (mean $\pm S D, 3.1 \pm 1.5$ ) in all patients, attributed to the effective periprostatic blockade. When the two groups were compared, there was a significant difference in VAS values. Likewise, a significant difference was observed between the two groups before and after the procedure (pre-biopsy and post-biopsy). However, this difference was not clinically significant because patients were evaluated regarding low VAS scores (Table 3).

\section{Study Limitations}

There were some limitations to this study. This study included only a relatively low number of patients. It was not possible to control pain sensation at every stage of the procedure, such as when the ultrasound probe was inserted into the anus, or the needle was inserted during the periprostatic blockage. The biopsy gun's sound was loud and made patients uncomfortable, although it had been tested before the procedures. Despite these limitations, the present study showed that listening to music and pre-education by watching an animation video

\begin{tabular}{|c|c|c|c|c|c|}
\hline & $\begin{array}{l}\text { Control } \\
(n=51)\end{array}$ & $\begin{array}{l}\text { Experimental } \\
(n=51)\end{array}$ & $\mathbf{P} 1$ & $\mathbf{P}^{2}$ & $\mathrm{P}^{3}$ \\
\hline \multicolumn{3}{|l|}{ VAS } & \multirow[b]{2}{*}{0.008} & \multirow[b]{2}{*}{$<0.001$} & \multirow[b]{2}{*}{$\begin{array}{l}0.02 \\
0.01\end{array}$} \\
\hline $\begin{array}{l}\text { Pre-test } \\
\text { Post-test }\end{array}$ & $\begin{array}{l}3.72 \pm 1.9 \\
4.72 \pm 1.2\end{array}$ & $\begin{array}{l}2.59 \pm 0.7 \\
3.7 \pm 1.4\end{array}$ & & & \\
\hline \multicolumn{3}{|l|}{ STAI } & \multirow[b]{2}{*}{0.001} & \multirow[b]{2}{*}{$<0.001$} & \multirow[b]{2}{*}{$\begin{array}{l}<0.001 \\
<0.001\end{array}$} \\
\hline $\begin{array}{l}\text { Pre-test } \\
\text { Post-test }\end{array}$ & $\begin{array}{l}40.1 \pm 2.3 \\
37.7 \pm 3.3\end{array}$ & $\begin{array}{l}36.5 \pm 36 \\
29.6 \pm 1.4\end{array}$ & & & \\
\hline \multicolumn{3}{|c|}{ Systolic Pressure $(\mathrm{mmHg})$} & \multirow[b]{2}{*}{$<0.001$} & \multirow[b]{2}{*}{0.001} & \multirow[b]{2}{*}{$\begin{array}{l}0.159 \\
0.044\end{array}$} \\
\hline $\begin{array}{l}\text { Pre-test } \\
\text { Post-test }\end{array}$ & $\begin{array}{l}138.1 \pm 9.0 \\
147.9 \pm 5.8\end{array}$ & $\begin{array}{l}140 \pm 8.4 \\
145 \pm 5.0\end{array}$ & & & \\
\hline \multicolumn{3}{|c|}{ Diastolic Pressure $(\mathrm{mmHg})$} & \multirow[b]{2}{*}{$<0.001$} & \multirow[b]{2}{*}{$<0.001$} & \multirow[b]{2}{*}{$\begin{array}{l}0.291 \\
<0.001\end{array}$} \\
\hline $\begin{array}{l}\text { Pre-test } \\
\text { Post-test }\end{array}$ & $\begin{array}{l}81.3 \pm 8.5 \\
96.6 \pm 2.3\end{array}$ & $\begin{array}{l}79 \pm 5.6 \\
90.8 \pm 5\end{array}$ & & & \\
\hline \multicolumn{3}{|c|}{ Heart Rate } & \multirow[b]{2}{*}{$<0.001$} & \multirow[b]{2}{*}{$<0.001$} & \multirow[b]{2}{*}{$\begin{array}{l}0.015 \\
0.019\end{array}$} \\
\hline $\begin{array}{l}\text { Pre-test } \\
\text { Post-test }\end{array}$ & $\begin{array}{l}79.6 \pm 2.7 \\
73.2 \pm 2.8\end{array}$ & $\begin{array}{l}77.4 \pm 4.1 \\
71.3 \pm 3.7\end{array}$ & & & \\
\hline \multicolumn{6}{|c|}{$\begin{array}{l}\mathrm{P}^{1}: \text { Comparison of pre-test and post-test control group values } \\
\mathrm{P}^{2}: \text { Comparison of pre-test and post-test experimental group values } \\
\mathrm{P}^{3} \text { : Comparison of control and experimental group values } \\
\text { VAS: Visual analoque scale, STAI: State-trait anxiety inventory }\end{array}$} \\
\hline
\end{tabular}

Table 3. Changes in evaluated variables between the experimental and control groups

\begin{tabular}{|l|l|l|l|}
\hline & Experimental group & Control group \\
\hline$\Delta$ VAS & $1.13 \pm 1.44$ & $1.0 \pm 2.3$ & 0.7 \\
\hline$\Delta$ STAI & $-6.8 \pm 3.9$ & $-2.4 \pm 4.0$ & $<0.001$ \\
\hline$\Delta$ Diastolic pressure & $5.5 \pm 9.4$ & $9.8 \pm 10.1$ & 0.048 \\
\hline$\Delta$ Heart rate & $11.8 \pm 7.2$ & $15.3 \pm 8.6$ & 0.045 \\
\hline VAS: Visual analogue scale, STAI: State-trait anxiety inventory & $-6.1 \pm 5.2$ & $-6.3 \pm 3.4$ & 0.086 \\
\hline
\end{tabular}


decreased anxiety, heart pressure and heart rate during a TRUSguided biopsy.

\section{Conclusions}

Watching the animation video and listening to music during the TRUS-guided biopsy procedure can be obtained quickly and had positive effects on patients. This method offers a safe option for patients with cardiac pathology, psychiatric problems and indications for re-biopsy in urological procedures.

\section{Acknowledgements}

Publication: The results of the study were not published in full or in part in form of abstracts.

Contribution: There is not any contributors who may not be listed as authors.

Conflict of Interest: No conflict of interest was declared by the authors.

Financial Disclosure: The authors declared that this study received no financial support.

\section{Ethics}

Ethics Committee Approval: The study has been approved by the Medicalpark Karadeniz Hospital Ethics Committee (approval no: 2001/18/108).

Informed Consent: All patients signed an informed consent form.

Peer-review: Externally peer-reviewed.

\section{Authorship Contributions}

Concept: H.T., Design: H.T., Data Collection or Processing: H.T., G.K.Ö., Analysis or Interpretation: H.T., Literature Search: H.T., Writing: H.T.

\section{References}

1. Irani J, Fournier F, Bon D, et al. Patient tolerance of transrectal ultrasound-guided biopsy of the prostate. Br J Urol 1997;79:608-610.

2. Chapple AB, Ziebland $S$, Brewster $S$, McPherson A. Patients' perceptions of transrectal prostate biopsy: a qualitative study. Eur J Cancer Care (Engl) 2007; 16:215-221.

3. Raber M, Scattoni V, Roscigno M, et al. Topical prilocaine-lidocaine cream combined with peripheral nerve block improves pain control in prostatic biopsy: results from a prospective randomized trial. Eur Urol 2008;53:967-973.

4. Rodríguez RRP, Dehesa TM, Zucharino AL, et al. Complications of prostatic echo-guided trans-rectal biopsy and tolerance depending on the patient and the operator. Study of 205 patients. Arch Esp Urol 2002; 55:509-521.

5. Tsivian $\mathrm{M}$, Qi $P$, Kimura $\mathrm{M}$, et al. The effect of noise-cancelling head $\neg$ phones or music on pain perception and anxiety in men undergoing transrectal prostate biopsy. Urology 2012;79:32-36.

6. Hsiang $\mathrm{CY}$, Lai $\mathrm{YH}, \mathrm{Wu} \mathrm{CH}$, et al. The effects of education in decreasing anxiety and postoperative pain in women with early-stage breast cancer. New Taipei J Nurs 2001;3:91-102.

7. Briffaux R, Merlet B, Normand G, et al. (Short or long schemes of antibiotic prophylaxis for prostate biopsy. A multicentre prospective randomised study). Prog Urol 2009;19:39-46.

8. Kilciler M, Demir E, Bedir S, et al. Pain scores and early complications of transrectal ultrasonography-guided prostate biopsy: effect of patient position. Urol Int 2007;79:361-363.

9. Song YS, Song ES, Kim KJ, et al. Midazolam anesthesia during rigid and flexible cystoscopy. Urol Res 2007;35:139-142.

10. McCaffery M. Nursing approaches to nonpharmacological pain control. Int J Nurs Stud 1990;27:1-5.

11. Yeo JK, Cho DY, Oh MM, et al. Listening to music during cystoscopy decreases anxiety, pain, and dissatisfaction in patients: a pilot randomized controlled trial. J Endourol 2013;27:459-462.

12. Lee DW, Chan KW, Poon CM, et al. Relaxation music decreases the dose of patient-controlled sedation during colonoscopy: a prospective randomized controlled trial. Gastrointest Endosc 2002;55:33-36.

13. Chang YE, Oh TH, Lee JW, et al. Listening to Music during Transrectal Ultrasound-Guided Prostate Biopsy Decreases Anxiety, Pain and Dissatisfaction in Patients: A Pilot Randomized Controlled Trial. Urol Int 2015;94:337-341.

14. Ebneshahidi A, Mohseni M. The effect of patient-selected music on early post-operative pain, anxiety, and hemodynamic profile in cesarean section surgery. J Altern Complement Med 2008;14:827-831.

15. Packiam VT, Nottingham CU, Cohen AJ, et al. No Effect of Music on Anxiety and Pain During Transrectal Prostate Biopsies: A Randomized Trial. Urology 2018;117:31-35.

16. Doering S, Katzlberger F, Rumpold G, et al. Videotape preparation of patients before hip replacement surgery reduces stress. Psychosom Med 2000;62:365-373.

17. Burns JL, Labbe E, Arke B, et al. The effects of different types of music on perceived and physiological measures of stress. J Music Ther 2002;39:101-116.

18. Magill-Levreault L. Music therapy in pain and symptom management. J Palliat Care 1993;9:42-48.

19. Cho SW, Choi HJ. Effect of Music on Reducing Anxiety for Patients Undergoing Transrectal Ultrasound-Guided Prostate Biopsies: Randomized Prospective Trial. Urol J 2016;13:2612-2614. 